\title{
Insulin Infusion Set Use: European Perspectives and Recommendations
}

\author{
Dorothee Deiss, MD, Peter Adolfsson, MD, PhD, ${ }^{2}$ Marije Alkemade-van Zomeren, $\mathrm{DNE}^{3}$ \\ Geremia B. Bolli, MD, Guillaume Charpentier, MD, Claudio Cobelli, PhD, Thomas Danne, MD, \\ Angela Girelli, MD, Heiko Mueller, DNE, Carol A. Verderese, BA, ${ }^{10}$ and Eric Renard, MD, $\mathrm{PhD}^{11}$
}

\begin{abstract}
Insulin pump users worldwide depend on insulin infusion sets (IISs) for predictable delivery of insulin to the subcutaneous tissue. Yet emerging data indicates that IISs are associated with many pump-related adverse events and may contribute to potentially life-threatening problem of unexplained hyperglycemia. The relative scarcity of published research on IISs to date, the heterogeneity of regional IIS practices, and the increasing demand for international standards guiding their use prompted convening of a panel of diabetologists and diabetes nurse educators last February, in Milan, Italy, to discuss a framework for optimizing IIS practice in Europe. The multinational panel was tasked, first, with identifying the often-overlooked IIS issues that can affect patients' experience of pump therapy-e.g., partial or complete blockage of the cannula, skin pathologies, unpredictable variations in insulin absorption, dislodgment, and the demands of site rotation and set changesand, second, with establishing direction for developing cohesive protocols to assure long-term success.

As reported in this article, the panel examined IIS-related complications of pump therapy encountered in clinical practice, considered country-wide policies to prevent and mitigate such complications, and updated priorities for improving IIS education on issues of device selection, skin care, and troubleshooting unexplained hyperglycemia. These recommendations may be more relevant with the possibility of closed-loop systems available in the near future.
\end{abstract}

Keywords: Insulin infusion sets, insulin pumps, unexplained hyperglycemia, lipohypertrophy, artificial pancreas

$\mathbf{R}$ ECENT CALLS FOR MORE SYSTEMATIC MONITORING of insulin pump therapy have focused attention on the safe and efficient use of insulin infusion sets (IISs). ${ }^{1-5}$ IISs are essential for reliable delivery of pumped insulin to the subcutaneous (SC) tissue, and their role in the outcome of pump therapy has been largely under-appreciated. According to a joint statement of the European Association of the Study of
Diabetes (EASD) and the American Diabetes Association (ADA), IIS issues have led to the greatest number of pumprelated recalls by the US Food and Drug Administration (FDA). ${ }^{2}$ The statement asserts that comparable information is not publicly accessible in Europe and emphasizes the need for transparent reporting systems aimed at distinguishing IIS-related adverse events from other problems of insulin

\footnotetext{
${ }^{1}$ Medicover Berlin-Mitte, Clinic for Endocrinology and Diabetology, Berlin, Germany.

${ }^{2}$ Institute of Clinical Sciences, The Sahlgrenska Academy at University of Gothenburg, Gothenburg, Sweden.

${ }^{3}$ Diabetes Policlinic, Maasstad Hospital, Rotterdam, The Netherlands.

${ }^{4}$ Department of Medicine, Perugia University School of Medicine, Perugia, Italy.

${ }^{5}$ Department of Diabetes and Endocrinology, Centre Hospitalier Sud-Francilien, Corbeil-Essonnes, France.

${ }^{6}$ Department of Information Engineering, University of Padova, Padova, Italy.

${ }^{7}$ Diabetes Center for Children and Adolescents, Kinder- und Jugendkrankenhaus AUF DER BULT, Hannover, Germany.

${ }^{8}$ Diabetes Care Unit, A.S.S.T. of Spedali Civili, Brescia, Italy.

${ }^{9}$ German Clinic for Diagnosis, Section for Pediatric Diabetes Therapy, DKD HELIOS Klinik, Weisbaden, Germany.

${ }^{10}$ The Diabetes Education Group, Lakeville, CT, USA.

${ }^{11}$ Department of Endocrinology, Diabetes, Nutrition, Montpellier University Hospital; Institute of Functional Genomics, UMR CNRS 5203/INSERM U1191, University of Montpellier, Montpellier, France.
}

(C) Dorothee Deiss, et al., 2016; Published by Mary Ann Liebert, Inc. This Open Access article is distributed under the terms of the Creative Commons Attribution Noncommercial License (http://creativecommons.org/licenses/by-nc/4.0/) which permits any noncommercial use, distribution, and reproduction in any medium, provided the original author(s) and the source are credited. 
infusion. ${ }^{2,6}$ In addition, it supports improved understanding of the interrelationships of IIS design, physiological and behavioral factors affecting day-to-day wear, and system factors, such as reimbursement and education, to promote successful pump therapy over time. Directing resources to this end may also help accelerate development of "artificial pancreas systems," which combine continuous glucose monitoring (CGM), algorithms, and pump technology for automated insulin delivery. ${ }^{7}$

Given the dearth of published research on IISs, the heterogeneity of regional IIS practices, and increasing demand for international standards guiding their use, ${ }^{1,8}$ a panel of diabetologists and diabetes nurse educators (DNEs) from France, Germany, The Netherlands, Italy, and Sweden convened in Milan, Italy in February 2016, to discuss a framework for optimizing IIS practice in Europe. This meeting followed a similar Expert Workshop held in 2015 in New Orleans, USA, that updated practical guidelines for IIS education put forth in a 2011 white paper of the American Association of Diabetes Educators. ${ }^{5,9}$ With the objectives of setting expectations for IIS technology and supplementing existing practical guidelines, ${ }^{5,9,10}$ the multinational panel reviewed IIS-related complications of pump therapy encountered in clinical practice, considered country-wide policies to prevent and mitigate such complications, and updated priorities for improving IIS education on issues of device selection, skin care, and troubleshooting unexplained hyperglycemia. A summary of the discussion follows.

\section{Etiologies of IIS Failure}

Inaccuracies of insulin delivery related to IISs have a multifactorial etiology that is not well understood. Even when best practices for insulin pump therapy are followed, infusion-set failure occurs in some patients, potentially leading to diabetic ketoacidosis (DKA). Sources of IIS failure that could result in disrupted insulin delivery are kinking, dislocation or leakage of the cannula, reservoir leakage, a loose connection between the reservoir and cannula, insulin precipitation in the cannula, or occlusions which may or may not trigger pump alarms (see below). ${ }^{3-5,11}$ In addition, impaired insulin action could result from inflammation at the site of the insertion, blood in the cannula or insertion site, a tissue reaction after a prolonged interval between infusion set changes, or the cannula being placed in unhealthy tissue (e.g., areas of lipohypertrophy).

Most studies evaluating IIS adverse events are based on patient questionnaires; consequently, events that are not readily viewable, such as blockage or occlusion, may be subject to interpretation. In a recent survey of 92 patients with type 1 diabetes, more than half of subjects reported issues with either kinking (64\%) or blockage (54\%), and approximately one-quarter noted the presence of lipohypertrophy (swelling and/or induration of fat tissue that may impair insulin absorption). ${ }^{3}$ Over $80 \%$ of the sets used by survey respondents in this study featured Teflon cannula.

An earlier nationwide pediatric surveillance of IIS use in Austria and Germany, in which $43 \%$ of subjects used a steel infusion set, revealed that $29 \%$ of patients had no IIS issues; however, the remaining $71 \%(n=475)$ reported an infusion set event. ${ }^{12}$ The most frequent of these was IIS occlusion $(34 \%)$. Others included blood in the IIS (14\%), skin redness
(11\%), and bent cannula (10\%). The finding that $36 \%$ of the reported complications occurred by the end of day 1 of IIS usage and $82 \%$ by the end of day 2 confirms the need for frequent set changes, especially in children.

In a prospective study of IIS function in 20 patients using either a steel or a Teflon cannula for up to 7 days, $30 \%$ of both types of sets were removed because of hyperglycemia that failed to respond following a correction dose, $13 \%$ because of pain at the infusion site, $10 \%$ were pulled out accidentally, $5 \%$ fell out because of loss of adhesion, $4 \%$ were removed because of infection, and $10 \%$ showed erythema and/or induration of $>10 \mathrm{~mm} .{ }^{4}$ The authors of this study concluded that the strongest predictor of set reliability was the individual patient, not the type of IIS.

Noting the continued expansion of pump use in Europe and the need for more robust evidence regarding IIS outcomes, the panel endorsed scientific initiatives that integrate data from healthcare professionals, pump companies, and local patient registries in order to define the actual frequency and mechanisms of infusion set failure. ${ }^{8}$

\section{Unexplained Hyperglycemia}

In addition to the common sources of IIS failure cited above, the panel singled out unexplained hyperglycemia as an "under-reported, under-estimated, and under-discussed", etiology, leading to a significant psychological burden and, potentially, discontinuation of pump therapy and/or DKA. ${ }^{13}$ In a multicenter, 13-week study with 256 subjects wearing an IIS with a Teflon cannula for a mean duration of 71 hours, approximately $61-68 \%$ of subjects reported one or more episodes of unexplained hyperglycemia and/or infusion set occlusion per month depending on the type of rapid-acting insulin used, and $30 \%$ experienced an occlusion alarm. ${ }^{11,14}$ Anecdotal evidence suggests that $30-50 \%$ of set removals are due to unexplained hyperglycemia, defined as a blood glucose level $>250 \mathrm{mg} / \mathrm{dL}$ that does respond to a bolus dose with no apparent medical, dietary, insulin dosage, or pump-related origin. Moreover, the time to occlusion alert may differ depending on the programmed basal rate, length of the infusion catheter tubing, and pump model. ${ }^{15}$

\section{Unexpected Flow Interruption}

Significantly, recent data have demonstrated that delayed and/or decreased insulin concentration during infusion associated with in-line pressure increases do not always trigger occlusion alarms. ${ }^{11,16-20}$ This finding has given rise to the identification of flow interruptions, sometimes called silent occlusions (defined as a continuous rise in in-line pressure for at least 30 minutes) in research studies, that may underlie some episodes of unexplained hyperglycemia in insulin pump users. As background, investigators installed pressure sensors into infusion lines to measure correlations between in-line pressure variability and insulin flow reliability during continuous basal intradermal infusion. In comparing the measurements to SC controls, they observed that marked increases in in-line pressure during the SC infusion periods (signifying flow interruptions) occurred over a 24-hour period without activating the insulin pump occlusion alarm. This discovery led to development of a novel side-ported cannula that reduces the impact of such pressure increases by enabling insulin flow out of two channels. Two separate studies comparing the 
effect of the novel IIS (BD FlowSmart ${ }^{\mathrm{TM}}$; Becton Dickinson and Co., Franklin Lakes, NJ) with a widely used device (Quick-set ${ }^{\circledR}$; Medtronic MiniMed, Northridge, CA) confirmed that the formation of dual depots from the side-ported cannula was associated with a $75 \%$ reduction in the occurrence of flow interruptions for at least 4 hours after insertion. ${ }^{11}$ This is clinically relevant because Teflon catheters have a 9\% to $15 \%$ failure rate (blood glucose value of $>250 \mathrm{mg} / \mathrm{dL}$ and not decreasing at least $50 \mathrm{mg}$ in 1 hour post-correction bolus) following insertion. ${ }^{4,21}$

\section{Choosing and Using an IIS}

As described below, educating patients in preventing IIS failure and troubleshooting possible causes is often timeconsuming and outside physicians' scope of work. ${ }^{8}$ Thus the panel stressed the need for educational tools and device designs that facilitate appropriate set selection, healthy IIS habits, and cohesive practice standards in the heterogeneous settings of European healthcare delivery.

\section{Selecting an IIS}

Options for choosing an IIS vary according to country and whether DNEs are part of the healthcare environment. In The Netherlands, for example, patients receive most of their pump education from DNEs, whereas in other countries timepressed physicians are often responsible for education and follow-up. ${ }^{8}$ Education may be protocol-driven, as in the Netherlands, or entirely customized, as in Sweden. Under all circumstances, a trained clinician should observe patients inserting their infusion set upon initiation of pump therapy. Set choice should be guided by patient/caregiver preference, age, duration of diabetes, skin characteristics, physical activity, and dexterity issues. ${ }^{5}$ Ideally, criteria for choosing an IIS should be discussed prior to ordering the insulin pump and different models should be available in the clinic for examination and discussion. If possible, clinicians should practice inserting an infusion set and wearing different sets themselves in order to appreciate patients' actual experience.

Citing video demonstrations as an important means of teaching patients about IIS features, the panel recommended development of an open-access, non-promotional website showing commercially available insulin infusion sets, together with related links to manufacturers' video demonstrations. It was noted, however, that such videos should not take the place of face-to-face education and informed recommendations from a knowledgeable healthcare professional. Table 1 presents general guidelines for helping patients choose an IIS. Relevant set features are cannula material, insertion angle (straight or angled), cannula length, connection (luer

\section{Table 1. Individualizing IIS Selection Based on Patient Factors ${ }^{5}$}

\begin{tabular}{|c|c|}
\hline Patient Factor & Infusion Set Considerations \\
\hline Age & $\begin{array}{l}\text { - } 90^{\circ} \text { insertion angle simpler for children learning to insert their own IISs } \\
\text { - Shorter IIS tubing length generally better for children and most adults } \\
\text { - Steel needle sets easier to teach and simpler to insert, less prone } \\
\text { to kinking and dislodgment }\end{array}$ \\
\hline Lean/muscular & - $30^{\circ}-45^{\circ}$ reduces risk of dislodgment for lean patients \\
\hline Pregnancy & $\begin{array}{l}\text { - } 30^{\circ}-45^{\circ} \text { angle of insertion preferred when abdominal tissue becomes } \\
\text { stretched } \\
\text { - Steel decreases risk of bent/obstructed cannula }\end{array}$ \\
\hline Dexterity and visual issues & $\begin{array}{l}\text { - Use of an autoinserter may be easier } \\
\text { - } 90^{\circ} \text { angle easier in cases of poor dexterity and/or hard-to-reach sites } \\
\text { - Audible "click" of sideway-pull disconnection/reconnection can be } \\
\text { reassuring to visually impaired; twist-and-pull sometimes easier to } \\
\text { manipulate }\end{array}$ \\
\hline Susceptibility to occlusions & $\begin{array}{l}\text { - Steel IISs eliminate kinking risk } \\
\text { - IIS with side-ported cannula may reduce risk of sub-alarm flow } \\
\text { interruptions due to in-line rises in pressure }\end{array}$ \\
\hline Insulin dose & $\begin{array}{l}\text { - Longer-length cannulae better for larger boluses ( } \geq 25 \text { units) and higher } \\
\text { basal rates }(\geq 2.5 \mathrm{U} / \mathrm{h})\end{array}$ \\
\hline Allergies and Infections & $\begin{array}{l}\text { - Reaction to Teflon or nickel in steel needle may dictate choice } \\
\text { - } 30^{\circ}-45^{\circ} \text { angle with viewing window allows monitoring for redness } \\
\text { around cannula insertion site }\end{array}$ \\
\hline Skin redness/tape allergies & $\begin{array}{l}\text { - Consider adhesive barriers (Skin-Prep, Cavilon) and/or under-bandage } \\
\text { (Fixomull-Stretch), hydrocolloid tapes (Mepilex-Lite, Comfeel Thin) }\end{array}$ \\
\hline $\begin{array}{l}\text { Lipohypertrophy, scarring, and/or } \\
\text { collagen pathologies due } \\
\text { to duration of diabetes }\end{array}$ & - Rotation of site crucial; some patients may need to resume injections \\
\hline Physical activity & $\begin{array}{l}\text { - } 30^{\circ}-45^{\circ} \text { angle reduces risk of dislodgment } \\
\text { - History of cannula kinking may favor steel }\end{array}$ \\
\hline Needlephobia & $\begin{array}{l}\text { - Simplicity of } 90^{\circ} \text { insertion angle may be preferred } \\
\text { - Use of a preloaded insertion device, rather than an IIS that needs } \\
\text { to be manually placed in the insertion device by the patient, may } \\
\text { be less stressful for some }\end{array}$ \\
\hline
\end{tabular}

IIS = insulin infusion set. 
lock or non-luer lock), tubing length, and inserter options. In particular, optimal cannula material-i.e., steel versus polymer (Teflon) - remains a matter for debate among European healthcare practitioners. The panel observed that a "trial and error" approach to IIS selection is not unusual in real-life settings. Thus patients who experience $\geq 1$ IIS failure per month should consult their clinician to review their technique or try a different set type.

\section{Steel versus Teflon Cannulas}

There is limited published data about the number of pump wearers in different countries using steel versus Teflon cannulas. Survey data indicate that steel cannulas are more commonly used in Europe than in the United States. ${ }^{22}$ The panel observed that Europe is moving significantly toward Teflon, with the exception of Germany, where approximately $40 \%$ of cannulas now in use are steel. In France, by contrast, steel cannulas are not used at all. Given the equivocal evidence in favor of or against these materials, the choice is often left up to the patient unless there are clear predisposing individual factors toward using one type over the other (Table 1). ${ }^{23}$ The panel generally recommended changing IISs every 2 days for steel and 3 days for Teflon. This change frequency is based on empirical evidence, however, and practice varies among patients and countries. ${ }^{22,24}$ For reasons still unknown, some patients can exceed advised wear-times without developing skin reactions or worsening of glycemic control, whereas others must change their sets more frequently than recommended to prevent adverse events. More research, including skin biopsies, will be needed to distinguish the mechanisms behind these individual differences.

\section{Establishing Healthy IIS Practices}

Infusion set problems frequently resolve once the patient adjusts his or her technique (see below), attends to adhesion and line-anchoring issues, and/or switches to a more suitable IIS. Owing to the short half-life of rapid- and short-acting insulin used in pumps, any disruption of insulin delivery can result in hyperglycemia within four to eight hours. If the incident occurs overnight, DKA may ensue in the morning. In a study of 30-minute IIS disconnection, blood glucose levels increased by $1 \mathrm{mg} / \mathrm{dL}$ for each minute (up to 3 hours) that basal insulin infusion was interrupted. ${ }^{25}$

The panel underscored the value of explaining common causes of IIS failure at the outset of pump therapy to minimize risk of future DKA and other metabolic derangements. ${ }^{26}$ Patients should be advised that IIS issues may occur even when devices are used correctly, and that inspection of the IIS at least twice daily in addition to frequent blood glucose measurement is necessary to set a course for proactive IIS management. Table 2 presents a checklist to prevent or, if necessary, remediate cycles of poor glycemic control related to IIS failure. The table is intended as a template for promoting awareness, and may be customized by healthcare practitioners in varied clinical settings. Key areas of IIS education include site selection, preparation, rotation, skin maintenance, and DKA prevention. Items should be verbally, visually, and manually reviewed with the patient, as appropriate, and entered into the medical record at each clinic visit.

\section{Site Selection and Rotation}

At the beginning of pump therapy, patients generally find IIS insertion easiest at viewable locations. The abdomen (avoiding bony protrusions and the umbilical area) or the outside front thigh is often chosen, but other common sites include upper buttocks, the back of the arm, the lower back, and, for pregnant women, just below the waistline at the side of the body. 5,9 The panel stressed that sites should be individualized according to patient preference. Areas near belts, waistbands, or zippers should be avoided. Patients who have difficulty inserting their infusion set manually may prefer a mechanical insertion device (autoinserter). Autoinserters are generally recommended when the cannula material is Teflon. However, all patients should be trained in techniques of manual insertion as well. Lifting a skin fold is often advised if there is minimal SC fat at the infusion site and the patient is using an angled set. The smallest diameter needle/cannula should be considered to reduce pain (or the perception of pain).

Patients should be educated early and regularly on the importance of inserting the cannula into healthy SC fat tissue, avoiding underlying muscle as well as areas of skin irritation, infection, scarring, "pump bumps" and lipohypertrophy. Lipohypertrophy is a thickened rubbery swelling of adipose tissue that may be soft or firm; pump bumps manifest as small reddish papules at insertion sites; and scarring feels like small to large firm lumps under the skin. Infusion sites should be rotated to minimize the risk of these deleterious side effects. Lipohypertrophy, in particular, may affect insulin absorption, potentially contributing to hyper- and hypoglycemia, as well as unpredictable glucose variability. ${ }^{27}$ Since the initial stages are usually easier to feel than to see, all patients who infuse insulin must have their sites visually inspected and palpated at each clinic visit, or at least once annually. Clinicians should inspect multiple sites (not just one chosen by the patient) using directional lighting while the patient is either in a standing position or lying down with knees bent. Two fingers should be used to apply downward pressure, working inward to feel for a hardened ridge or "step up" from the soft tissue surrounding the site. Once the borders of the lesion are determined, the area should be outlined (using a skin-safe pen with the patient's consent), measured, and, if possible, photographed for uploading to the electronic medical record (EMR). ${ }^{10}$ Patients should be encouraged to self-inspect sites-preferably while in a standing position and using a hand lotion or gel- to target healthy tissue for set insertion. Frequent blood glucose monitoring is advised upon transitioning from unhealthy to healthy tissue since insulin needs are often reduced when absorption is improved. It should be noted, too, that poor absorption from infusing into damaged tissue may lead to delayed onset of insulin action and increased risk of hypoglycemia due to overlapping correction boluses (stacking). ${ }^{28}$

Strategies for correct rotation technique have not been formally established, but conventional wisdom supports inserting the cannula approximately 2 inches away from the old site for angled sets, approximately 1 inch away for $90^{\circ}$ sets, and at least 2 inches from current CGM sites. ${ }^{5}$ Securing the infusion line about 2 inches away from the set with a piece of tape, creating what is often referred to as a "safety loop," can help to keep the cannula in place and reduce the risk of dislodgment. Moreover, it has been surmised that set insertion in a supine position, such as lying down in bed, may lead to 
Table 2. Sample IIS Education Checklist

\begin{tabular}{|c|c|}
\hline Goal & Steps (check when covered) \\
\hline $\begin{array}{l}\text { Guide optimal IIS } \\
\text { selection }\end{array}$ & $\begin{array}{l}\text { Counsel patient on deciding factors: } \\
\square \text { Lean/muscular body type } \\
\square \text { Activity level } \\
\square \text { Visual acuity } \\
\square \text { Age } \\
\square \text { Dexterity } \\
\square \text { History of unexplained } \\
\text { hyperglycemia }\end{array}$ \\
\hline $\begin{array}{l}\text { Reduce the risk of } \\
\text { infection at IIS sites }\end{array}$ & $\begin{array}{l}\text { Counsel patient on: } \\
\square \text { Clean work space } \\
\square \text { Hand washing } \\
\square \text { Wiping top of vial with alcohol } \\
\square \text { Disinfection of site if obviously unclean } \\
\text { or patient is prone to infection } \\
\square \text { Being alert to redness, rash, inflammation }\end{array}$ \\
\hline $\begin{array}{l}\text { Individualize site } \\
\text { selection according } \\
\text { to patient preference } \\
\text { and needs }\end{array}$ & $\begin{array}{l}\text { Counsel patient on site options: } \\
\square \text { Abdomen (avoiding bony protrusions } \\
\text { and umbilicial area) } \\
\square \text { Outside front thigh } \\
\square \text { Upper buttocks } \\
\square \text { Back of the arm } \\
\square \text { Lower back } \\
\square \text { For pregnant women, below waistline } \\
\text { at the side } \\
\square \text { Avoid areas near waistbands, belts, } \\
\text { or zippers }\end{array}$ \\
\hline $\begin{array}{l}\text { Ensure proficiency } \\
\text { in IIS setup } \\
\text { and insertion }\end{array}$ & $\begin{array}{l}\text { Counsel patient on/demonstrate: } \\
\square \text { Filling reservoir/cartridge } \\
\square \text { Connecting reservoir to tubing } \\
\square \text { Priming (if applicable) } \\
\square \text { Clearing air bubbles from reservoir } \\
\text { and tubing } \\
\square \text { Insertion with auto-inserter (if applicable) } \\
\square \text { Optimal insertion time (before meal; } \\
\text { never before bed) } \\
\square \text { Inspecting pump, tubing, and pump site } \\
\text { once or twice daily; immediately after } \\
\text { physical activity or if pump is pulled } \\
\text { or banged }\end{array}$ \\
\hline $\begin{array}{l}\text { Promote healthy } \\
\text { site rotation } \\
\text { and set-change } \\
\text { practices }\end{array}$ & $\begin{array}{l}\text { Counsel patient to: } \\
\square \text { Change sets every } 2 \text { days for steel, every } \\
3 \text { days for Teflon (allowing for individual } \\
\text { wear time differences among patients) } \\
\square \text { Insert new infusion set in healthy tissue } \\
\text { ( } 2 \text { inches away from old site for angled } \\
\text { sets, } 1 \text { inch for } 90^{\circ} \text { sets, and two inches } \\
\text { from CGM sites) } \\
\square \text { Self-inspect sites for signs of infection, } \\
\text { irritation, "pump bumps," and } \\
\text { lipohypertrophy } \\
\square \text { Increase frequency of blood glucose } \\
\text { monitoring when transitioning from } \\
\text { unhealthy to healthy tissue }\end{array}$ \\
\hline
\end{tabular}

cannula kinking or occlusion afterwards when changing body position. Although more research is needed to understand the effects of body position on insulin flow, especially during sleep, inserting the set while standing may be preferable.

\section{Site Care and Adhesion}

Skin maintenance and attention to adhesion issues are crucial to preventing site irritation and cannula dislodgment. These topics should be emphasized at the outset of patient training and refreshed at least annually. Departing from practice in the United States, where cleaning the skin with non-alcoholic wipes is recommended, the panel agreed that disinfection of the infusion site is not necessary if patients employ normal hygiene practices, such as washing with mild soap and water. Nevertheless, antimicrobial body washes,
Table 2. (Continued)

\begin{tabular}{|c|c|}
\hline Goal & Steps (check when covered) \\
\hline Detect lipohypertrophy & $\begin{array}{l}\text { Counsel patient on visual and manual site } \\
\text { inspection and demonstrate technique. }\end{array}$ \\
\hline $\begin{array}{l}\text { Address/preempt } \\
\text { adhesion problems }\end{array}$ & $\begin{array}{l}\text { Counsel patient to: } \\
\square \text { Monitor adhesion and use adhesive } \\
\text { products as necessary } \\
\square \text { Use underbandage and/or overbandage } \\
\text { to reinforce set stability } \\
\square \text { Apply non-deodorant antiperspirant } \\
\text { to clean site if sweat is the issue }\end{array}$ \\
\hline $\begin{array}{l}\text { Troubleshoot } \\
\text { IIS-specific issues }\end{array}$ & $\begin{array}{l}\text { Collect information from patient } \\
\text { self-report, review of diabetes } \\
\text { management software (pump, glucose } \\
\text { data), and clinical examination } \\
\text { to distinguish issues such as: } \\
\square \text { Unpredictable absorption of insulin } \\
\text { due to lipohypertrophy } \\
\square \text { Kinking and blockage of cannula } \\
\square \text { Cannula dislodgment } \\
\square \text { Flow interruptions }\end{array}$ \\
\hline $\begin{array}{l}\text { Establish formal } \\
\text { plan for DKA } \\
\text { prevention and } \\
\text { intervention }\end{array}$ & $\begin{array}{l}\text { Explain potential for DKA; outline action } \\
\text { plan (sample below): } \\
\square \text { Investigate unexpected interruption } \\
\text { of insulin flow in the presence of } \\
\text { unexplained hyperglycemia } \\
\square \text { Be on the watch for early signs } \\
\text { of DKA (eg, thirst, nausea, vomiting, } \\
\text { fruity breath) } \\
\square \text { If symptoms are present, check blood } \\
\text { glucose and ketones (blood preferable } \\
\text { to urine) } \\
\square \text { If glucose }>250 \text { mg/dL, administer } \\
\text { correction bolus with pump } \\
\square \text { If blood glucose does not } \\
\text { normalize within } 2 \text { hours, administer } \\
\text { correction dose manually (with pen } \\
\text { or syringe) } \\
\square \text { Blood ketone level }>0.7-1.5 \text { mmol/L } \\
\text { (urine, negative to small) may require } \\
\text { larger insulin dose } \\
\square \text { Replace IIS and refill cartridge from } \\
\text { new insulin vial } \\
\square \text { Monitor ketones and glucose hourly } \\
\text { until situation resolves } \\
\square \text { Blood ketones }>1.3 \text { mmol/L (Urine, } \\
\text { moderate to large) warrants consult with } \\
\text { diabetes team (may vary with country- } \\
\text { specific protocols) } \\
\square \text { Blood ketones }>3 \text { mmol/L (urine ketones, } \\
\text { large) requires emergent care. } \\
\square \text { Provide contact information for clinical } \\
\text { assistance and emergent care }\end{array}$ \\
\hline
\end{tabular}

$\mathrm{CGM}=$ continuous glucose monitoring; DKA = diabetic ketoacidosis; IIS = insulin infusion set.

such as Hibiclens ${ }^{\circledR} /$ Octenisan ${ }^{\circledR}$, may be helpful in patients prone to skin infection. Hands should be washed thoroughly before IIS insertion and the top of the insulin vial should be cleaned with alcohol.

Products that form a barrier between the set and the skin, where oil and moisture can accumulate, may be applied topically before insertion to keep the set in place longer and prevent skin irritation. A non-deodorant antiperspirant, used on the site approximately 10 minutes before insertion (to allow for drying), may also enhance adhesion for patients who sweat profusely, are highly physically active, and/or have thick body hair. Another option for stabilizing the set is the use of flexible "tape" that adheres to both the skin and the IIS catheter. Covering the top of steel sets in particular with an adhesive "overbandage" can provide further reinforcement. Adhesive barriers, such as Skin-Prep/Cavilon ${ }^{\mathrm{TM}}$, or 
underbandage, such as Fixomull ${ }^{\circledR}$-Stretch and hydrocolloid tapes (Mepilex ${ }^{\circledR}$ Lite, Comfeel ${ }^{\circledR}$ Thin), are commonly used. It is important to avoid stretching the tape over the skin, which can make removal difficult.

\section{Priming}

The panel was divided on the issue of priming (filling the cannula after insertion), though agreed that the preferable timing for insertion is before a meal and never before bedtime. Priming was customary in Germany, for example, until it was observed that there was little effect on hyperglycemia. Thus the current trend is to time the insertion with the meal bolus and "push the insulin through." If priming is practiced, the recommended fill amount is $0.3 \mathrm{U}$ for a $6 \mathrm{~mm}$ polymer cannula and $0.5 \mathrm{U}$ for a $9 \mathrm{~mm}$ polymer cannula. All patients should be instructed to monitor their blood glucose levels two hours following infusion set changes (making sure to plan insertion schedules accordingly). ${ }^{26}$ Additionally, patients should always fill the reservoir with insulin that is room temperature to avoid air bubbles entering the infusion line. Formation of large enough bubbles $(>2 \mathrm{~cm})$ has the potential to replace insulin, which in turn could lead to hyperglycemia or increased ketones in blood. ${ }^{23}$

\section{Managing IIS Failure and DKA}

When a patient presents with IIS failure, patients and clinicians should: 1) examine the site, skin, and line anchoring; 2) review blood glucose and CGM data (if available) for unexplained hyperglycemia, and: 3 ) elicit information about the surrounding circumstances in order to better understand ways to intervene and prevent recurrence. 5,26

Interruptions of insulin flow should be investigated in any patient with unexplained glycemic variability, unexplained hyperglycemia, or frequent hypoglycemia/hyperglycemia. Questions that may help clarify the problem are: 1) Do correction boluses sometimes not work? 2) Do some highs only correct when you change your infusion set? 3) How many days do you usually wear an infusion set? 4) Does the skin where you wear your infusion set look different from other parts of your body? 5) How often do you experience hyperglycemia with no apparent cause $?^{5}$

Evidence of unexplained hyperglycemia warrants particular vigilance in the presence of sudden glucose elevation $(>250 \mathrm{mg} / \mathrm{dL}$ ) that is unrelated to a meal and accompanied by nausea or vomiting. Acknowledging that protocols vary in different countries and patient groups, the panel offered general recommendations for DKA prevention as follows.

If glucose levels do not normalize within 2 hours of administering a correction bolus, the patient should check his or her blood ketones. It was the opinion of the panel that urine ketone determination should be abandoned since ketones show up late in urine compared with blood and also decrease later after supplemental insulin is administered. Since ketones in the blood or urine signal an advanced failure in insulin delivery, the patient should also administer rapid- or fast-acting insulin by pen or syringe, based on his or her correction dose algorithm. The current infusion set and infusion reservoir/cartridge should be replaced during this time as well. The panel noted that a blood ketone level of $>0.7-$ $1.5 \mathrm{mmol} / \mathrm{L}$ (urine ketones, negative to small) may require a larger dose of insulin (e.g., twice the correction dose). If blood ketones are above $1.3 \mathrm{mmol} / \mathrm{L}$ (urine ketones, moderate to large), the patient should call the diabetes team for advice about additional insulin replacement, since this level of ketones indicates initial risk for acidosis. Blood ketones $>3 \mathrm{mmol} / \mathrm{L}$ (urine ketones, large) require emergent care. ${ }^{29}$

\section{Leveraging Information to Improve Care}

Given increasing demands on Western European healthcare systems, the panel stressed the need for studies to support the cost-effectiveness of pump practices, supplies, and access to diabetes education, which is not routinely reimbursed. ${ }^{8}$ It was noted that such studies may be facilitated by more widespread use of diabetes management software (e.g., CareLink $^{\circledR}$, Diasend ${ }^{\circledR}$ ) that reveals specific information, such as total daily insulin dose (including percentage basal versus bolus insulin, which can indicate impaired insulin absorption), bolusing patterns, and frequency of IIS changes. Such electronic information could be uploaded to large data repositories for translational research, or used in office settings as a basis for troubleshooting unexplained hyperglycemia. In the Netherlands and Sweden, for example, downloaded pump, blood glucose, and/or CGM data are shared among members of the diabetes team, either via printouts or at group meetings, and analyzed collaboratively in order to target problems that may later be discussed during the office visit. This method is consistent with general trends among European healthcare authorities to support potentially cost-saving education and team-based care for chronic disease. ${ }^{8}$

Formalizing pump training through centers of excellence and reimbursement programs is an additional avenue for motivating practitioners to use uploaded data and IIS management tools, such as the checklist in Table 2 of this article. Physicians, in particular, should be taught to recognize patterns of unexplained hyperglycemia, deduce the frequency of infusion set change (which may be different from patient report), and identify skin pathologies that affect IIS selection and subsequent usage over time. The training program should include documentation practices compatible with a centralized, publically accessible international database for AE reporting. ${ }^{2}$

\section{Education}

In Western Europe, diabetes education is often left to physicians and diabetes teams who have limited time for the effort needed to become proficient in all aspects of pump therapy management. Insulin pump manufacturers may fill this gap by providing their own training programs (although some countries such as France do not allow industry involvement). The panel agreed that, given current realities, optimal, ageappropriate practices for IIS usage should be featured more prominently in pump manuals and brochures, avoiding brand bias. ${ }^{30}$ It was also observed that the goal of adapting sophisticated insulin infusion devices to the day-to-day needs of patients will depend in part on more widespread participation of DNEs in mainstream healthcare. This evolution should come with improved reimbursement of training and services, such as educating patients about IIS options and site care. Cost-effectiveness studies are expected to show that attendant reductions in hospitalizations for DKA and other complications of IIS failure would make this investment worthwhile. 
TABle 3. High-Level Recommendations for IMPRoving IIS OUTCOMES

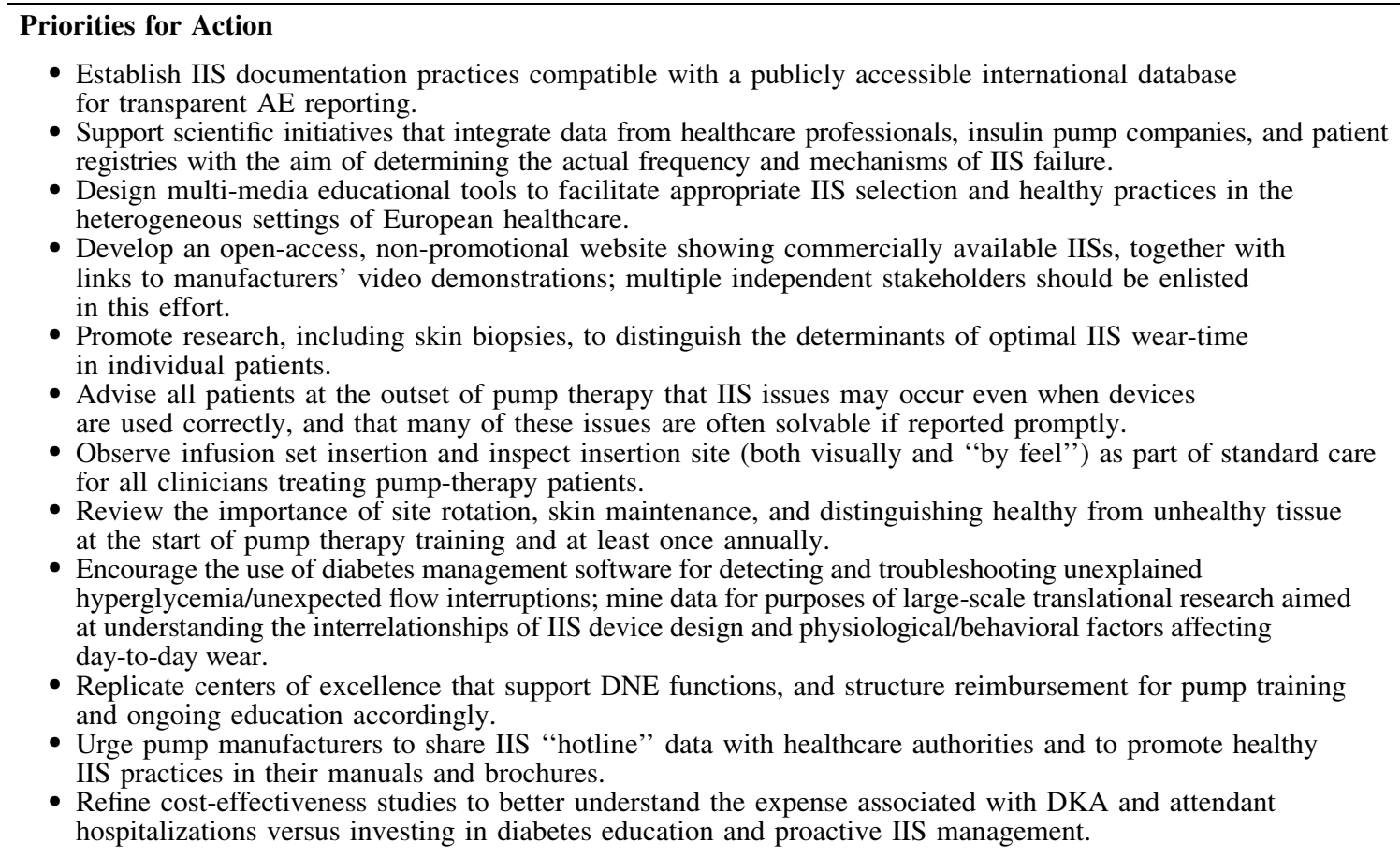

$\mathrm{AE}=$ adverse event; $\mathrm{DKA}=$ diabetic ketoacidosis; $\mathrm{DNE}=$ diabetes nurse educator; $\mathrm{IIS}=$ insulin infusion set.

\section{Conclusion}

Emerging data that IISs are implicated in a large percentage of reported as well as still unrecognized pumprelated AEs have led to a renewed focus on IIS design and usage. A novel side-ported cannula that mitigates flow interruptions exemplifies the potential for pursuing sciencebased design solutions. However, technology will work only as well as the education surrounding it. Thus, more opportunities for IIS education will be needed. This prospect is particularly challenging in some European countries, where physicians carry full responsibility for teaching and followup of pump-therapy patients. The goal of this article is to highlight the often-overlooked IIS issues that can affect patients' experience of pump therapy-i.e., partial or complete blockage of the cannula, skin pathologies, unpredictable variations in insulin absorption, dislodgment, and the demands of site rotation and set changes - and provide impetus for developing cost-efficient DNE-driven education to better assure long-term success. To date, off-label extended use of IISs has not been evaluated, so optimal wear-time in real life remains unknown. A summary of high-level recommendations is provided in Table 3 .

\section{Acknowledgment}

Funding for this project was provided by BD BiomedicalDiabetes Care.

\section{Author Disclosures}

D.D. has received research support from BD, DexCom, Medtronic, and Roche.

P.A. has received lecture honoraria from Novo Nordisk, Eli Lilly, Sanofi, Roche, Medtronic, Dexcom, Menarini, and
Abbott, and participated in Advisory Boards for Eli Lilly, Abbott, Roche and Sanofi. P.A. is one of the founders and board member of Diasend Inc.

M.A.Z. has no disclosures to report.

G.B.B. has received honoraria for consultation and advice from Sanofi, Eli Lilly, Menarini.

G.C. has no disclosures to report.

C.C. has patent applications related to glucose sensors and the artificial pancreas; he has received non-financial support from Roche and Dexcom, and received research support, managed by University of Padova, from Dexcom, Sanofi, Adocia; he is a consultant/advisor for Novo Nordisk.

T.D. has received research support or served as a consultant for Abbott, AstraZeneca, Bayer, BD, Boehringer, DexCom, Eli Lilly, Medtronic, Novo Nordisk, Roche, Sanofi, and Ypsomed.

A.G. has no disclosures to report.

H.M. is a consultant for Medtronic (German-SwitzerlandAustria), Eli Lilly (Germany), Sanofi (Germany), Bayer Healthcare, and all regional German pharmacists associations.

E.R. is a consultant/advisor for Menarini Diagnostics, Abbott, BD, Cellnovo, Dexcom, Eli Lilly, Johnson \& Johnson (Animas, LifeScan), Medtronic, Novo Nordisk, Roche Diagnostics and Sanofi, and has received research grant/ material support from Abbott, Dexcom, Insulet and Roche Diagnostics.

C.A.V. has no disclosures to report.

\section{References}

1. Heinemann L, Krinelke L: Insulin infusion set: the Achilles heel of continuous subcutaneous insulin infusion. J Diabetes Sci Technol 2012;6:954-964. 
2. Heinemann L, Fleming GA, Petrie JR, Holl RW, Bergenstal RM, Peters AL: Insulin pump risks and benefits: a clinical appraisal of pump safety standards, adverse event reporting, and research needs: a joint statement of the European Association for the Study of Diabetes and the American Diabetes Association Diabetes Technology Working Group. Diabetes Care 2015;38:716-722.

3. Pickup JC, Yemane N, Brackenridge A, Pender S: Nonmetabolic complications of continuous subcutaneous insulin infusion: a patient survey. Diabetes Technol Ther 2014;16: 145-149.

4. Patel PJ, Benasi K, Ferrari G, et al.: Randomized trial of infusion set function: steel versus teflon. Diabetes Technol Ther 2014;16:15-19.

5. Evert AB, Bode BW, Buckingham BA, et al.: Improving patient experience with insulin infusion sets: practical guidelines and future directions. Diabetes Educ 2016;42: 470-484.

6. Boulton AJ, Del Prato S: Regulation of medical devices used in diabetology in Europe: time for reform? Diabetologia 2012;55:2295-2297.

7. JDRF: Request for expressions of interest: improved longevity for sub-cutaneous insulin infusion. RFA 20150806 http://grantcenter.jdrf.org/wp-content/uploads/2012/12/ Infusion-Set-Longevity-EOI.pdf. Accessed March15, 2016.

8. Renard E: Insulin pump use in Europe. Diabetes Technol Ther 2010;12 (Suppl 1):S29-S32.

9. American Association of Diabetes Educators: Insulin pump therapy: best practices. https://www.diabeteseducator.org/ practice/practice-documents/white-papers. Accessed March 15, 2016.

10. Frid A, Kreugel G, Grassi G, et al.: New insulin delivery recommendations. Mayo Clin Proc 2016; in press.

11. Gibney M, Xue Z, Swinney M, Bialonczyk D, Hirsch L: Reduced silent occlusions with a novel catheter infusion set (BD FlowSmart): Results from two open-label comparative studies. Diabetes Technol Ther 2016;18:136-143.

12. Liebner T, Holl R, Heidtmann B, et al.: Insulinpumpenkatheter: komplikationen im Kindes- und Jugendalter. Diabetologie und Stoffwechsel 2011;6:S52.

13. Ross PL, Milburn J, Reith DM, Wiltshire E, Wheeler BJ: Clinical review: insulin pump-associated adverse events in adults and children. Acta Diabetol 2015;52:1017-1024.

14. Van Bon AC, Bode BW, Sert-Langeron C, DeVries JH, Charpentier G: Insulin glulisine compared to insulin aspart and to insulin lispro administered by continuous subcutaneous insulin infusion in patients with type 1 diabetes: a randomized controlled trial. Diabetes Technol Ther 2011;13: 607-614.

15. Van Bon AC, Dragt D, DeVries JH: Significant time until catheter occlusion alerts in currently marketed insulin pumps at two basal rates. Diabetes Technol Ther 2012;14;447-448.

16. Keith S, McVey E, Pettis R: High sensitivity occlusion detection using fluid pressure monitoring during basal infusion. Presented ADA 2013, Chicago. Diabetes 2013; 62(Suppl 1):A249-250.

17. Gibney M, Hirsch L, Swinney M, Xue Z: Continuous subcutaneous insulin infusion (CSII) sets - Reduced flow interruptions with a novel investigational catheter infusion set. Presented ATTD 2015. Diabetes Technol Ther 2015; 17(Suppl 1):A-8.
18. Bolick N, Morel DR, Gerth SS, Woodley WD, Pettis RJ: Reduction of silent occlusion occurrence during continuous subcutaneous insulin infusion. Presented ATTD 2015. Diabetes Technol Ther 2015;17(Suppl 1):A-37.

19. Bolick NG, Sutter D, Pflug B, Hirsch L, Bode B, Pettis RJ: Performance qualification of a novel subcutaneous insulin infusion set using medical imaging. Presented American Diabetes Association $75^{\text {th }}$ Scientific Sessions. Boston, USA. 2015. Diabetes 2015;64(Suppl 1):A-279.

20. Bolick NG, Morel DR, Alarcon J, et al.: In vivo flow evaluation and correlation to insulin pharmacokinetics of continuous subcutaneous insulin infusion sets. Presented American Diabetes Association $75^{\text {th }}$ Scientific Sessions. Boston, USA. 2015. Diabetes 2015;64(Suppl 1):A274-A275.

21. Renard E, Guerci B, Leguerrier AM, Boizel R; Accu-Chek FlexLink Study Group: Lower rate of initial failures and reduced occurrence of adverse events with a new catheter model for continuous subcutaneous insulin infusion: prospective, two-period, observational, multicenter study. Diabetes Technol Ther 2010;12:769-773.

22. Walsh J, Roberts R, Weber D, Faber-Heinemann G, Heinemann L: Insulin pump and CGM usage in the United States and Germany: results of a real-world survey with 985 subjects. J Diabetes Sci Technol 2015;9:1103-1110.

23. Heinemann L: Insulin infusion sets: a critical reappraisal. Diabetes Technol Ther 2016;18:327-333.

24. Johansson UB, Adamson U, Lins PE, Wredling R: Patient management of long-term continuous subcutaneous insulin infusion. J Adv Nurs 2005;51:112-118.

25. Zisser H: Quantifying the impact of a short-interval interruption of insulin-pump infusion sets on glycemic excursions. Diabetes Care 2008;31:238-239.

26. Ponder SW, Skyler JS, Kruger DF, Matheson D, Brown BW: Unexplained hyperglycemia in continuous subcutaneous insulin infusion: evaluation and treatment. Diabetes Educ 2008;34:327-333.

27. Famulla S, Hövelmann U, Fischer A, et al.: Insulin injection into lipohypertrophic tissue: blunted and more variable insulin absorption and action, and impaired postprandial glucose control. Diabetes Care 2016 jun; dc160610. http:// dx.doi.org/10.2337/dc16-0610.

28. Walsh J, Roberts R, Bailey T: Guidelines for optimal bolus calculator settings in adults. J Diabetes Sci Technol 2011; 5:129-135.

29. Wolfsdorf JI, Allgrove J, Craig ME, et al.: ISPAD Clinical Practice Consensus Guidelines 2014. Diabetic ketoacidosis and hyperglycemic hyperosmolar state. Pediatr Diabetes 2014;15 Suppl 20:154-179.

30. Lange K, Swift P, Pańkowska E, Danne T: Diabetes education in children and adolescents. Pediatr Diabetes 2014; 15:77-85. doi:10.1111/pedi.12187.

Address correspondence to: Dorothee Deiss, MD Medicover Berlin-Mitte Hausvogteiplatz 3-4 10117 Berlin, Germany

E-mail: dorothee.deiss@medicover.de 